\title{
The Importance of the State's Entrepreneurial Role, Business Support Services, and Technological Assistances to the Development of Vietnamese SMEs
}

\author{
Thanh Hai Nguyen \\ Department of Management, Monash University, Australia \\ E-mail: Thanh.Nguyen@Buseco.Monash.edu.au \\ Quamrul Alam \\ Department of Management, Monash University, Australia \\ E-mail: Quamrul.Alam@Buseco.Monash.edu.au \\ Daniel Prajogo \\ Department of Management, Monash University, Australia \\ E-mail: Daniel.Prajogo@buseco.monash.edu.au \\ Ai Ngoc Duong \\ Institute of Financial Science and Insurance, University Claude Bernard Lyon 1, France \\ E-mail: aingoc.duong@axa.fr
}

\begin{abstract}
This paper reports the findings of a study that examines the evolving relationships between the state's entrepreneurial role and market factors such as business support services, business training and professional development, technological and information support services and SMEs' development in Vietnam. This study uses an institutional approach to study how the entrepreneurial state influences the creation of market factors in Vietnam. The findings suggest that the state has taken some committed initiatives in attracting external support, building infrastructure both tangible and intangible, and enabling structural flexibility for the growth of SMEs. The state's entrepreneurial role is of special importance since it can coordinate with existing market factors to provide policy support, external resources, and institutional infrastructure for the growth of SMEs in Vietnam. However, inconsistency in policy, slow pace of market reform in selected business areas, and inadequate resource allocation practices have hindered the development of SMEs.
\end{abstract}

Keywords: Transitional economy, SMEs, State and Market

\section{Introduction}

The Central and Eastern European (CEE) experience suggests that the reduction of government ownership and control in business, business support infrastructure, and financial support, the legal and institutional framework, and cluster and network relationships play a fundamental role for business development (Katz, 1995; Assaf, 1998; Konopielko and Bell, 1997; McIntyre, 2002). In a similar pattern, the public sector has been playing a key role in strengthening the development of a dynamic private enterprise sector and efficient market in the context of an Asian socialist market economy model. State and market have been working together to create sustainable conditions for private sector business development and especially for the development of SMEs.

This paper examines the role of the state institutions in creating market conditions for SME growth. The adequacy of the policy regime and the effectiveness of the support infrastructure have been discussed to identify the problems of the market development process under the socialist market economy model of Vietnam.

\section{Factors impacting on SMEs in Vietnam}

\subsection{State Policies for SME Growth}

Support policies for SMEs vary from country to country and from developed countries to less developed countries due to differences in business contexts, culture and the level of industrialization. The CEE experience suggests that business support infrastructure, financial support, legal and institutional framework, and cluster and network relationships play a vital role for business development. According to Batra and Mahmood (2003), SMEs in developing countries in East 
Asia receive support from local governments in the form of micro finance, interventions to increase private sector training, technology development, and market information. China, Malaysia, Indonesia and Thailand benefited from these policy reforms, network relationships, cluster linkage to markets, and the new support infrastructure (Brimble, Oldfield and Monsakul, 2002; Harvie, 2001; Tambunan 2005; and Harvie, 2002. In Vietnam, policy support is a critical factor for SME growth.

\subsection{Business Support Services}

In CEE countries, privatisation was introduced to restructure large state-owned enterprises (SOEs) into SMEs (Gibb and Lyapunov, 1996). McIntyre (2002) recommends a contrary solution whereby disassembling large firms may not sustain SME growth. In Asia, due to the absence of an adequate support regime, this idea has proven reasonable, since SMEs in China still need large firms for support. From the experiences of CEE countries, Dallago, and McIntyre (2003) state that SMEs are not themselves sufficient for growth without the proper development of institutions and supporting structures.

\subsection{Supporting Infrastructures}

Wattanapruttipaisan (2002) proposes that competitiveness can be leveraged by factors other than location and natural resources such as: on-going access to global information and knowledge (market standards, marketing opportunities and technology); participation in clusters of firms, networks with suppliers, producers or complementary products; distributors and consumers; and on-going learning and improvements in efficiency and flexibility. This network relationship created a new information flow and knowledge base for SMEs that could be the model for the efficiency of resource distribution to SMEs by way of numerous policy packages from the state and the market.

\section{Methodology}

\subsection{Conceptual Framework}

Institutional theories referred to by Petri (1995), Assaf (1998), Brimble, Oldfield and Monsakul (2002), Harvie (2002), Tambunan (2005), Ha and Swierczek (2003), and Gibb and Lyapunov (1996) provide an understanding of the factors supporting SME development in developing countries. These authors infer that a well-defined support regime from the state can coordinate with existing market factors to provide policy support, external resources, and institutional infrastructure for the growth of SMEs.

A conceptual framework was applied to examine the evolving relationship between state and market and the impact of that relationship on local SMEs (see Fig.1 in the appendix). The conceptual framework included enabling or hindering factors associated with (1) the entrepreneurial role of the state through policies, resources and infrastructure, and (2) market factors.

\subsection{Research Methodology}

This paper uses qualitative data drawn from a number of semi-structured interviews held in Ho Chi Minh City, Vietnam. In order to identify key themes in this data, a content analytic approach was taken. 17 respondents were selected randomly and interviewed in June 2006. Semi-structured interviews were conducted mainly in Ho Chi Minh City.

Based on the conceptual model, a group - comprehensive questionnaire was developed to address the overall research issue of identification of the effectiveness of SME-related policies. Identified issues were analysed through applying NVivo-assisted themed qualitative analysis methods.

\section{Major finding}

\subsection{Business Support Services \& Human Resource Training and Professional Development}

There are shortages of good technical advisors and information. According to a respondent, he experiences difficulty in seeking qualified information and does not know where to seek advice. It seems that supporting agencies have failed to meet the demands of SMEs. Respondents have doubts about the roles of supporting agencies and the quality of technological consulting services. Information provided is too general and there is a shortage of necessary information about incentive policies and legal regimes available for SMEs. According to the findings, a common SME problem is the lack of formal linkages among businesses since most of the cooperation is through informal relationships. This has created no leap-frog approach for entrepreneurial development through which cooperation among potential businesses for production, sharing information, and supply chain and outbound value chain activities could evolve. In the absence of such an entrepreneurial culture, SMEs do not know where to seek advice and where there might be opportunities for cooperation: "Quality of technological consulting services is so poor. If we want to buy hi-tech equipment (for food processing) we have to learn ourselves since we do not know who to ask for advice" (F3-G1). As a result, SMEs find it risky to engage in international businesses with foreign partners. As claimed by respondents, the weak and unsynchronized role of supporting institutions in facilitating networking and cooperation also could be the reason for the slow growth of SMEs. On the other hand, the findings also indicate that there is a lack of cooperation among supporting institutions. Support in training is the government's indirect assistance to improve SMEs' managerial skills 
and to equip SMEs with professional skills. As a result, SMEs will have more chances to improve their products' quality, reducing the cost of production, and increasing their competitiveness.

The findings indicate that some government officers' inability to adapt to a market-oriented economy has created annoyance and difficulties for SMEs. According to interviewees, the insufficient skills and knowledge of executive officers has actually discouraged them from working with SMEs effectively and actively. Despite the fact that the government has tried to equip their staff with capabilities and knowledge in business management, it seems that the government officers who are currently involved with the private sector do not have enough skills and competency to adapt to the current economic development situation. As a result, SMEs are currently becoming the victim of red tape and corruption from those government officers. Furthermore, the implication of supporting policies would be invalidated due to the inadequate training of these officers: "Executive officers do not know clearly about the laws. They feel embarrassed in supporting and guiding SMEs to follow the laws. It could be seen that executive staff are incapable of helping SMEs effectively" (SMEs 1-G3). Surprisingly, all respondents claimed that the roles of these supporting agencies are still not strong in providing high quality advisory and training programs for SMEs. Training programs are not practically focused and are too general, as stated by a respondent: "The issue is how to select the most suitable training program that can satisfy SMEs' needs. Information is so general and there is no special information for food manufacturers in technology, corporate management, MKT" (F4-G1). In addition, as SMEs may not be able to pay for the qualified services that are offered by support agencies, they are neglected by consulting firms. Moreover, there is really a gap between SMEs' needs and advisory services' capability in satisfying SME demands: "SMEs do not know what to ask and advisors do not understand or fail to identify the need of SMEs" (R5-G2)

\subsection{Technology and Information Support Services}

A number of common technologically related issues were referred to by respondents such as legal barriers and ineffective policy regimes concerning property rights; patents and trademarks; technological transferring; and importation of used equipment. Also, there was a lack of formal network linkages and technological cooperation among technological research institutions, between SMEs and supporting institutions, and with other firms. "Technological transfer is mostly from SOEs to SOEs" (F2-G1). The shortage of funds for investment and for technological development and the existence of an ineffective legal framework have prevented SMEs and research institutions from cooperating with each other. Hence, the findings indicate that there is evidence of a deficient overall national technological research and development strategy. "The current intellectual and property laws are being implemented but still can not effectively handle any possible dispute. There are still some limitations in the legal framework such as limitations in importing used manufacturing equipment. The fact is that many SMEs can not afford to buy high-tech equipment" (F4-G1).

In regard to the low level of technological facilities of supporting institutions, one respondent comments that, "Technology is out of date, and there is a lack of motive power in innovation. The supporting capability of research institutions is vague. Equipment is out of date with a technology lag of 2-3 generations compared to regional countries" (SMEs1-G3).

\section{Discussion and conclusion}

\subsection{Business Support Services}

\subsubsection{Lack of legal framework to support consulting services for SMEs}

Tax for business consulting firms may be significantly different from a state-owned supporting and training agency to a non-state-owned firm. According to the results, key areas for advisory services, training programs and projects to support SMEs consist of legal consulting for start up firms, taxation reports, general market information, and marketing and business development support activities. Advisory activities for technological innovation and adequate provision of information have not been considered as a primary focus of those supporting institutions and business supporting services for SMEs. This observation is consistent with the statement of Pham (2002) that, in a survey conducted by VCCI, approximately $48.7 \%$ of interviewees have received advice from other business entrepreneurs. On the contrary, only $9.6 \%$ of the interviewees have received advice from professional advisors. SMEs found difficulties in accessing necessary information and advice for business developments. SMEs currently rely heavily on informal resources of information and public media rather than on formal sources of information from their supporting institutions and particularly from professional advisors.

\subsubsection{Lack of formal linkages among businesses}

In the absence of capable supporting institutions and regulatory regimes that can act as facilitators to encourage networking and linkages among SMEs and other business sectors, obviously strategic linkages for cooperation seem to be impossible. SMEs need networking and collaboration among important stakeholders to bridge the resource and capability gaps. The current infrastructure and regulatory regime have not been able to create market conditions that facilitate networking and mutual beneficial relationships. The findings demonstrate that there is poor linkage among 
academic and research institutions, government management entities, industrial and business associations, supporting services and SMEs. Under such an unfavorable environment, lending organizations are reluctant to lend capital to SMEs. Moreover, the legal system and inadequate support infrastructure have made the business environment more uncertain and risky. As a result, emerging SMEs find it difficult to attract capital from both local and foreign financial sources.

\subsubsection{Deficiency in the legal framework and weak roles of supporting agencies}

The instability of policies and frequent changes in regulatory and related policies has generated significant risks for SMEs. Those constraints have not encouraged SMEs to seek for cooperation opportunities, strategic alliances or industrial subcontracting. Despite being mentioned in trade laws, these activities have not been defined clearly. The regulatory framework for industrial subcontractors, supporting industries, business associations, and business advisory services does not adequately sustain SME development. Pham (2002) observed that no specific law provisions contain the necessary requirements for business consulting services such as the roles and responsibilities of advisory services, codes of ethics, professional knowledge, and principles of arbitrations of conflict of interest. There is also the unavailability of regulations and a tax policy for SMEs using advisory services. Hence, business supporting and advisory services have not been considered as a critical industry in the national lists of professional careers. It seems that there are no clear-cut definitions about business supporting services and even clear-cut definitions about SMEs. As stated by Pham (2002), some business supporting services were ranked in the group of "other financial intermediaries' supporting activities". Others were ranked in the lists as "other business trading activities". As result, the quality of services from private advisory and supporting agencies is still questionable. On the other hand, due to unclear definitions, some SMEs can receive much help from the assistance programs, while others who do not know clearly about the government's favorable policies can not approach or receive the benefits from those supporting programs.

\subsubsection{Poor Quality of Human Resource Training and Professional Development}

An unqualified and unskilled labor force is really a significant impediment for both the government and SMEs. The inadequate structures of skilled labor could be due to insufficient training and the educational system. The fact is that, while there is a redundancy of unskilled labor, skilled labor is rare. According to Pham, (2002), the percentage of those who have attended some business administration training programs was only about $37.8 \%$ of the interviewed SME directors. Having identified the importance of training programs for SMEs, the Vietnamese government has been conducting numerous corporate management projects. These supports are in the form of training, provision of information, marketing support, technological advice, and advisory services for business development. However, it should be emphasized that any public support for SMEs from the government should not be understood in the sense of free-of-charge or partly subsidized. It is because there will be no huge financial subsidies that can satisfy the needs of entrepreneurs for training. On the contrary, business development and supporting services will have to play a key role in facilitating the development of the private sector. Although the Communist Party and the Vietnamese government have made many efforts to train their executive officers, it seems that many of them are incapable of working in a marketoriented economy or of supporting private SMEs effectively. Inflexibility and resistance to change due to fear of the unknown, fear of losing power, and fear of losing interests are the most common problems. Many of them are not adequately trained in any basic business managerial skills and legal knowledge.

According to figures from the Organization Department of the Government in the survey of $2001,30 \%$ of executive officers failed to fulfill successfully their assigned tasks. An additional $30 \%$ of staff who were currently working in the public administration sector did not meet the civil service's requirements. At the local level, $60 \%$ of civil staff did not have university degrees. And, more importantly, many corrupt officers have been creating difficulties for SMEs and Vietnamese residents $(\mathrm{Vu} 2001)$. It is fair to say that there are gaps between the supporting policies and the implementations of these policies. This is due to the fact that managerial regimes and executive officers are unable to adapt to the rapid changes of the new market-oriented environment. It could be said that there is a shortage of an overall strategy for training civil staff effectively. It seems that the government has not successfully addressed the specific needs of training for their civil staff in terms of practical applications with basic skills of business and state management, information technology and foreign language courses. More importantly, this shows the defects of the current national education programs in updating their curricula to accord with market and economic development trends. And finally, the complex and overlapping management regimes with unclearly designed functions have added more difficulties.

According to Ho, Do and Chu (2002) only 5.13\% of private SMEs owners have college qualifications, 10-15\% SMEs owners have short-term managerial training (below 6 months) and $48.4 \%$ have no formal qualification. This example shows the SMEs' significant needs for managerial and professional skills training. There are two problems that need to be highlighted. First, the quality of the training services is still questionable. Second, SMEs face difficulties in accessing these training services due to a gap between SMEs' needs and advisory services' capability. Consistent with Pham (2002), only $9.6 \%$ of the interviewed SMEs in the VCCI 2001 study received advice from professional consulting firms while $48.7 \%$ of them have sought advice from informal sources. This example helps clarify why SMEs tend to focus on 
informal sources of advice rather than formal advisory services. Regarding the gap between SMEs' needs and advisory services' capability, supporting services do not pay attention to SMEs because SMEs may not be able to pay for the services. Unfortunately, business supporting and training services have formed in a disorganized way, and lack an overall developmental strategy and proper operational regimes. As a result, business supporting and training services are operating incoherently without mutual cooperation. Some services and training providers do not focus on quality of the services, which makes SMEs incredulous. Others fail to identify the necessary needs of SMEs.

\subsection{Technological Development and Information Services}

\subsubsection{The Elimination Of Technological Transfer Barriers And The Encouragement of R\&D}

According to Le (2006), Vietnamese entrepreneurs' demands for technological innovation were quite low. Vietnamese SMEs' expenses for technological innovation accounted for only $0.2-0.3 \%$ of total revenue, in comparison with $5 \%$ in Indian SMEs or 10\% in Korean SMEs. This figure indicates that SMEs are not proving able to upgrade their technology and equipment to high technological development levels.

\subsubsection{Problems of Legal Barriers and Ineffective Policy Regimes for Technological Transfer}

It could be said that the current policy for technological development is mostly focused on the management of technological transfer. Unfortunately, technological transfer activities are only occurring among

SOEs. Hence the policy is only on the supporting side of those SOEs and may not be profitable for SMEs. On the other hand, there are inadequacies in regulations and policies about tax, credits, customs, and investment. Furthermore, high commission expenses would be key barriers deterring technological transfer activities, as well as not creating favorable conditions for IT software technology to develop. There are several problems relating to policy regimes and legal barriers such as: there is no adequate competition legislation and anti-monopoly policies that can eliminate the privileges of SOEs and encourage SMEs to innovate in technological development. There are several defective rules and policy inconsistencies in patents and trade marking, technological transfer and research development, and in investment funds for risky business. Those inadequacies have turned out to be significant barriers for SMEs to overcome, as well as broadening the gap between demand and supply of technological development and supporting services. There are no specific technological support policies for SMEs. Although the government has been offering incentives for businesses that are applying modern technology; those incentives are not really suitable to SMEs' abilities. SMEs are poor in resources and can not successfully afford high-tech, while the incentives are for businesses in all sectors who actively conduct research and development activities as well as employing new modern technologies. As a result, there are big gaps between policy implications and policy design. Furthermore, most of the technological transfer activities are cases of horizontal conversion from business to business at the same level, rather than from large firms to smaller firms.

\subsubsection{The problems of poor technological development, and poor internal resources}

As stated by Le (2006), the results of a recent study conducted in 2003 show that $86 \%$ of the respondents complained about the inadequate technological market or the weakness of technological supporting services. The technological market has failed to meet the demands for technological research development and transfer. $32 \%$ of the respondents in this study claimed that technological researchers and suppliers did not know who would be their targeted customers for selling their technological research products, while $29 \%$ of respondents complained that they did not know where to buy those technological products and technologies. The other $26 \%$ revealed that there was no real technological market for SMEs, since only state-owned technological research institutions and state-owned technological supporting services were operating. About $43 \%$ of the total respondents in this survey claimed that there were not any or inadequate rules and policies for regulating and defining the methods of technological transfer activities in the technological market. For that reason, supporting technological development activities are underdeveloped for supporting SME growth. On the other hand, those supporting policies seem to pay more attention to SOE technological research and development rather than supporting and facilitating the sustainability and growth of SMEs in the private sector. Although facing an urgent need for technological innovations and improving their competitive advantages, private manufacturing SMEs in Vietnam do not have the capability of adopting new technology due to their inadequate labor force, inadequate capital and managerial skills. Most of SME equipment and production facilities are traditional technologies, manual or semi-automatic controls, and from SOEs and domestic sources which are already out of date by two to three or even four technological generations in comparison with regional countries and even with other larger Vietnamese businesses in the same industry. Backward equipment and facilities are disposed by SOEs and are then adopted by SMEs as their production facilities. There are quite a few private manufacturing SMEs who can actually import high-tech facilities from overseas apart from mature and large private manufacturers. Together with financial and human resource constraints that deter SMEs from further upgrading technological equipment, SMEs also face a numbers of obstacles such as the shortage of technological information, and lack of necessary supporting services and networking linkages for cooperation and resource utilization among SMEs and technological supporting entities. This is consistent with what 
we have found in our study about the problem of technological research and development services in Vietnam.

\subsubsection{Problem of poor networking, linkages for cooperation and poor technological supporting services for SMEs}

Supporting institutions are unable to identify and meet the actual needs of SMEs for technological research and development, and technological transfer activities. It is fair to say that, quite different from corporate management and business supporting services, technological supporting services are mostly provided by state-owned institutions because those organizations have stronger technological advantages and stronger resources for investment in technological innovation. Although many private and semi-private academic and research institutions have been established, they are not capable of helping SMEs. They are also dispersed in different areas. However, the connections, linkages and networking between those supporting institutions with SMEs, SMEs with SMEs and other large firms, and among those supporting institutions do not really exist. Obviously, there is a significant gap between the supply and demand sides for technological research and developments. According to Pham (2002), only 4\% of FDI firms had approval of technological transfer contracts from the state. An unexpected result was that most of the technological transfer was "under the table". This has led to many instances where SMEs did not choose a suitable technology for production and invested heavily in high-technology equipment or purchased backward equipment that can not help improve their competitive advantage. There is strong evidence to say that an imperfection between the formulation of technological support policy and its implications exists. During the interview process, some respondents did mention the recent introduction of a "technological incubation center". However, this concept has not actually being considered as critical to technological research and development support for SMEs from concerned parties. The reason is that technological incubation centers are not just the place to develop SMEs but also need numerous business support services to integrate and create a strong networking, linkage relationship to satisfy the diversified and increasing demands of SMEs in responding to globalization and economic development trends. On the other hand, the lack of coherent linkages between academic institutions, research institutions, SMEs and other business entities is partly caused by a shortage of the necessary regulatory framework. Business supporting services for market research, marketing, technological information, and business brokerage services are considered by the concerned parties as "usual intermediaries" for coordination. This is the reason why there are no strong linkages among business and institutional entities. Further, where a very high distrustful culture (due to strong social discrimination and the poor image of Vietnamese private SMEs) exists, it is very difficult to build mutual trust and seek cooperation to utilize technological and other resources efficiently.

To conclude, the current gap between the supply and demand sides for technological research and information, training and development, and business support services would be not easy to solve in the short term. The findings suggest that the state's entrepreneurial role is of special importance since it can coordinate existing market factors to provide support policies, infrastructure resources, and support institutions for SME development in Vietnam. This study highlights that inadequate policy regimes and inadequate market factors may become hindering factors instead of being enabling factors for SME growth if the Government and supporting institutions do not play a key role in acting as facilitators for the efficient distribution of resources. The proposed model could be a good example for further examination of the evolving relationship between the State and market factors in similar transitional and developing countries.

\section{Acknowledgements}

Our special thanks to the valuable contribution, Dr Jeffrey Keddie, Department of Management, Monash University made to the preparation of this paper. The earlier version of this refereed paper was accepted (on 3-3-2008) for presentation at the 5th International Conference on Service Systems and Service Management (ICSSSM'08), 2008, Melbourne, Australia.

\section{References}

Assaf, G.B. (1998). Enterprise restructuring in central and Eastern Europe (CEE) and the former Soviet Union: The roles of technical assistance. In Cook C, Kirkpatrick C., and Nixson F. (Eds), Privatization, Enterprise development and Economic reform: Experiences of developing and transitional economies, USA: Edwards Elgar.

Batra, G., and Mahmood, S. (2003). Direct support to private firms: Evidence on effectiveness. World Bank policy research working paper 3170 .

Brimble, P., Oldfield, D., and Monsakul, M. (2002). Policies for SME recovery in Thailand. In: Harvie, C., and Lee, B.C. (Eds), The role of SMEs in National Economies in East Asia. Singapore: Edward Elgar.

Dallago B., and. McIntyre, R.J. (2003). Small and Medium enterprises in Transitional economies, Basingstoke and New York: Houndmills, Palgrave Macmillan, 2003.

Gibb, A., and Lyapunov, S. (1996). Creating small business out of large enterprises", in Levitsky, , J. (Eds), Small business in transition economies: promoting enterprise in central and Eastern Europe and the former Soviet Union. UK: IT publication, 1996. 
Ha, T.T., and Swierczek, F.W. (2003). Motivation, entrepreneurship and the performance of SMEs in Vietnam. Journal of Enterprising Culture, vol 11(3): 47-68.

Harvie, C. (2002). China's SME: Their evolution and future prospects in an evolving market economy. In Harvie, C., and Lee, B.C. (Eds), The role of SMEs in National Economies in East Asia. Singapore: Edward Elgar.

Havie, C. (2001). Competition policy and SMEs in Vietnam. Working paper series 2001, WP 01-10, Department of economic, Department of economic University of Wollongong, 2001.

Ho, X.P., Do, M.T., and Chu, M.P. (2002). Financial supports for the development of SMEs:, Monographic book, Hanoi: Financial Publishing House.

Katz, S. (1995). Some key development issues for transitional economies-East and West” Konopielko, L., and Bell, J. (1997). Reinventing aid for SMEs in Eastern Europe: Lessons from the implementation of the Struder Programme. Policy review section.

Le, D.D. (2006). Businessmen, business entrepreneurs and economic reform, Ho Chi Minh City: The Youth Publishing House, Saigon Economic Times, p. 27.

McIntyre, R.J. (2002). Small enterprises in transition economies: Causal puzzles and policies relevant research". Economic science of contemporary Russia, vol 5,(1): pp. 121-141 (English version).

Petri, P.A. (1995). The lesson of East Asian Success: A primer for transitional economies, in in Naya, S.F., and Tan, J.L.H. (Eds), Asian transitional economies: challenges and prospects for reform and transformation. Singapore: Institute of Southeast Asian Studies.

Pham, T.H. (2002). Creating good jobs by the support policies to develop SMEs. Hanoi: The National Political Publishing House.

Tambunan, T. (2005). Promoting Small and Medium Enterprises with a clustering approach: A policy experience from Indonesia. Journal of Small Business Management 43 (2): 138-154.

Vu, Q.T. (2001). Business entrepreneurs in the market oriented economy. Hanoi: The National Political Publishing House, p. 441, 2001.

Wattanapruttipaisan, T. (2002). Promoting SME development: Some issues and suggestion for policy consideration". [Online]. Available: http://unpan1.un.org/intradoc/groups/public/documents/APCITY/UNPAN011410.pdf.

\section{Appendix}

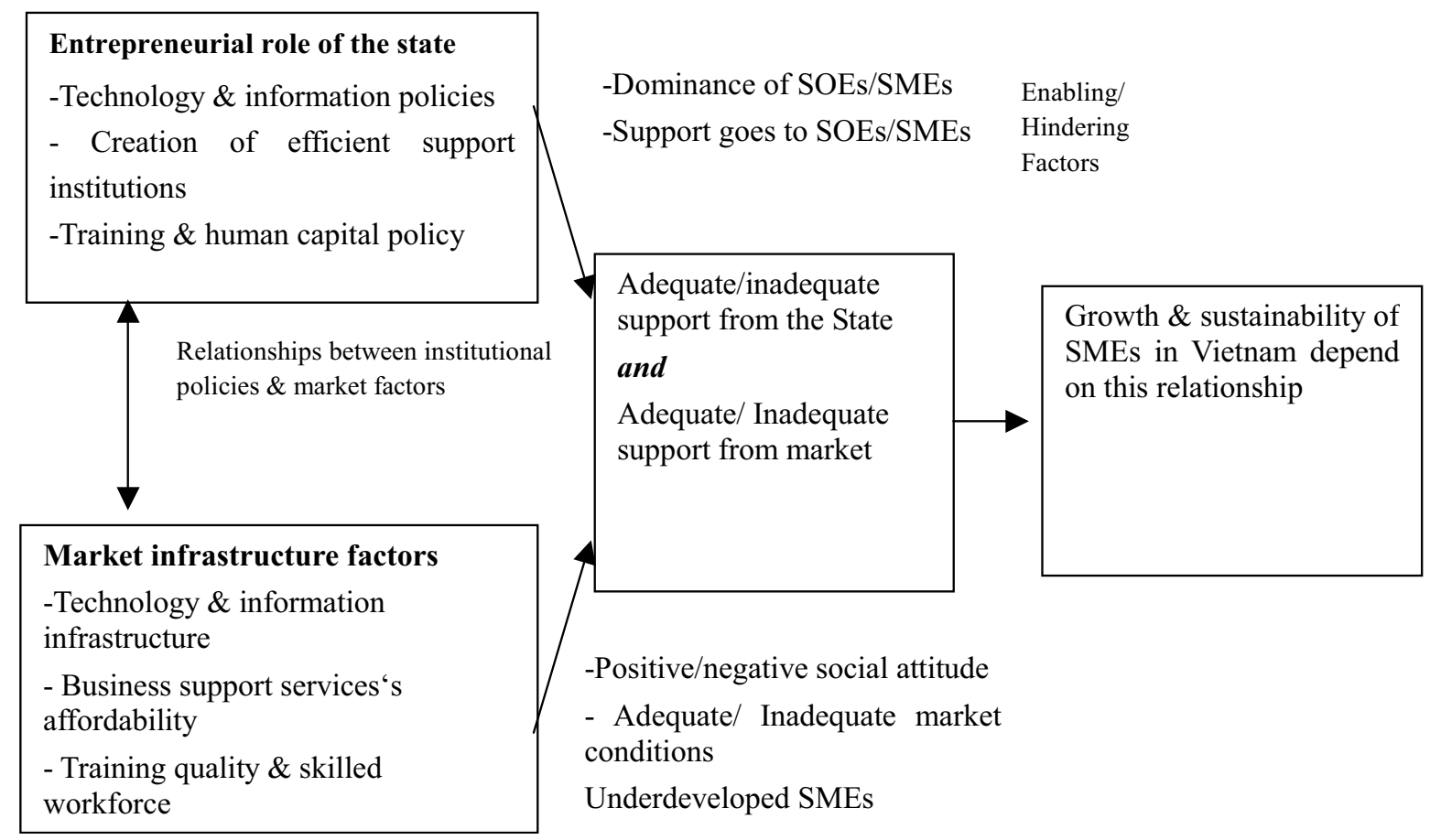

Figure 1. The Evolving Relationships between State and Market Factors impacting on SMEs in Vietnam 